\title{
Rise and fall of coeliac disease 1960-85
}

\author{
D A KElly, A D PHILlips, E J ElliotT, J A DIAS, AND J A WALKER-SMITH
}

Queen Elizabeth Hospital for Children, London

SUMmARY A total of 192 children who presented with coeliac disease to Queen Elizabeth Hospital for Children from 1960-85 were reviewed in order to investigate the frequency and the age of presentation. There was a clear peak in the number of children presenting from 1971-5, and although the numbers declined subsequently they have remained at a level similar to numbers found before 1971. There was no difference in the mode of presentation but there was a definite increase in the age of presentation over the time period reviewed. Breast fed babies presented later than bottle fed babies ( 14 compared with 9 months) despite a similar age of gluten introduction. Similarly bottle fed babies and breast fed babies presented later after $1975(10 \cdot 5$ compared with 7 months, and 18 compared with 9.5 months, respectively). Before 1975 the median age of gluten introduction was significantly less than that after 1975 ( 2 compared with 4 months) and the age of gluten introduction correlated with the age of presentation. It is concluded that breast feeding and the age of gluten introduction may influence the age of presentation of childhood coeliac disease but no clear reasons for the rise in incidence in the 1970s have been determined. It does not appear that the disease is declining, however, in recent years children have tended to present later in life.

Recent studies in the United Kingdom have suggested a decline in the numbers of children presenting with coeliac disease since $1972 .{ }^{1-3}$ This decrease in numbers may be due to stricter diagnostic criteria, to differences in infant feeding practices, or to other environmental factors such as a decrease in the incidence of acute gastroenteritis in infancy. ${ }^{4}$

In 1974 the Department of Health and Social Security (DHSS) encouraged breast feeding and the later introduction of gluten into the diet in infancy. ${ }^{5}$ In order to establish whether these recommendations were associated with any change in feeding patterns and to investigate the frequency and presentation of childhood coeliac disease all children diagnosed with coeliac disease who presented to Queen Elizabeth Hospital for Children from 1960-85 were reviewed.

\section{Patients and methods}

A retrospective study was performed of all children with coeliac disease who were diagnosed between 1960 and 1985 at Queen Elizabeth Hospital for Children. Children were included if they fulfilled (1) the diagnostic criteria proposed by the European Society for Paediatric Gastroenterology and Nutri- tion (ESPGAN) ${ }^{6}$ or (2) part of the ESPGAN criteria. These children included (a) those who were already on a gluten free diet but who were only included if they had a subsequent positive gluten challenge (that is, a histological relapse on gluten with or without clinical symptoms) or, (b) those who were over 2 years with an abnormal proximal small intestinal biopsy specimen consistent with coeliac disease who responded clinically to a gluten free diet but who were awaiting confirmation of the diagnosis by gluten challenge.

A computerised data base was compiled for each patient detailing age and mode of presentation, dietary history, ethnic origins, and laboratory findings. Breast feeding was defined as any infant who was breast fed regardless of how short a time this was and this was not necessarily exclusive. For purposes of analysis, where the information was available, it was divided into those fed for one month or less, for one to six months, and for greater than six months. Children who were bottle fed had never been breast fed.

\section{Results}

A total of 218 children were provisionally diagnosed 
as having coeliac disease from 1960-85. Twenty six were subsequently shown to have transient gluten intolerance and were not included in the study. Of the remaining 192, 81 fulfilled ESPGAN criteria, 37 had a positive gluten challenge, and 74 had a single abnormal biopsy specimen. One hundred and seventeen $(90 \%)$ of 130 children were white $(15 \%$ of whom were of Irish origin), four (3\%) were Asian, and the remaining nine $(7 \%)$ were of mixed races. Data was not available on the other 62 children.

Most children presented in a classical manner with diarrhoea, failure to thrive, abdominal distension, and buttock wasting; $18(17 \%)$ presented with anaemia (table 1). There was no noticeable difference in the mode of presentation with time. Seven children presented with delayed bone age and one child with rickets.

\section{FREQUENCY OF DIAGNOSIS}

Examination of the numbers of children diagnosed at this hospital each year showed a small peak of cases in the early 1960s (fig 1). This represented confirmation of clinical diagnosis by small intestinal biopsy, which was introduced at that time. In the early 1970 s there was a larger peak that diminished after 1975, although numbers remained at a similar level to those found before the 1970s. The observed peak (1972-5) was significantly different from the expected frequency of diagnosis at that time period and from the observed frequencies for the other years $\left(\chi^{2}\right.$ test $\left.p<0 \cdot 001\right)$. Consideration of these patients by year of birth showed a similar peak in the early 1970s (fig 2) with numbers reducing subsequently to a pre-1971 level. In 1985, no child under 2 years was diagnosed as having coeliac disease.

Table 1 Clinical features of childhood coeliac disease at Queen Elizabeth Hospital 1960-85

\begin{tabular}{lr}
\hline & $\begin{array}{l}\text { No }(\%) \text { of } \\
\text { children }\end{array}$ \\
\hline Presenting symptoms $(\mathrm{n}=192):$ & $125(65)$ \\
Diarrhoea & $98(51)$ \\
Failure to thrive & $61(32)$ \\
Weight <3rd centile & $28(14)$ \\
Height <3rd centile & $69(36)$ \\
Vomiting & $62(32)$ \\
Anorexia & \\
Presenting signs $(\mathrm{n}=192):$ & $103(54)$ \\
Abdominal distension & $72(37)$ \\
Wasting & $18(17)$ \\
Anaemia* $(\mathrm{n}=108):$ &
\end{tabular}

${ }^{*}$ Hacmoglobin concentration $<90 \mathrm{~g} / 1$.

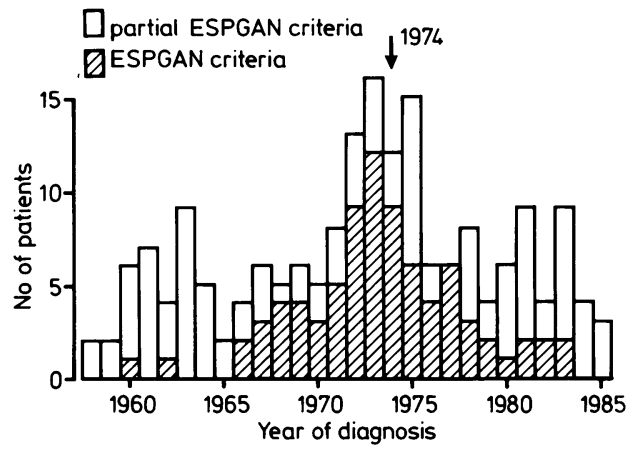

Fig 1 Year of diagnosis of 192 children with coeliac disease at Queen Elizabeth Hospital 1960-85. (From Diseases of the Small Intestine in Childhood. Third edition, 1988. By J A Walker-Smith. Reproduced with permission of Butterworth Scientific Ltd.)

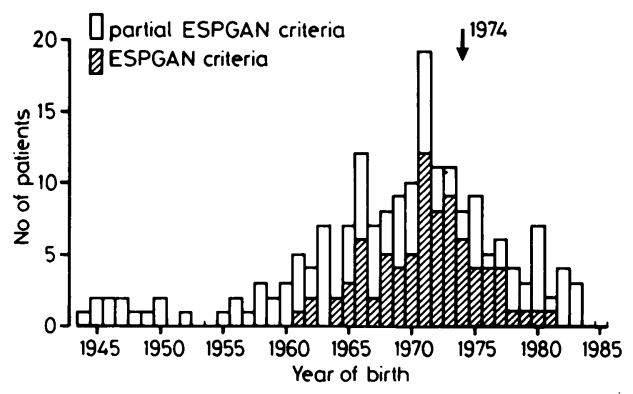

Fig 2 Year of birth of 192 children with coeliac disease at Queen Elizabeth Hospital 1960-85. (From Diseases of the Small Intestine in Childhood. Third edition, 1988. By J A Walker-Smith. Reproduced with permission of Butterworth Scientific Ltd.)

Examination of the mean age of presentation per year of diagnosis showed variation from year to year (fig 3). The overall mean age of presentation was 24 months. In comparison, using the $\chi^{2}$ test, the mean age in the first seven years (1965-71) was significantly lower (mean $=10$ months, $p=<0.01)$ and the mean age in the last seven years $(1979-85)$ was higher (mean $=38$ months, $\mathrm{p}<0.05)$. The mean age in the middle seven years (1972-78) was not different to the overall mean (mean $=23$ months, $p>0.05$ ). Thus there was a significant increase in the age of presentation over the 21 years under study.

AGE OF GLUTEN INTRODUCTION

Although there was a clear trend towards a later introduction of gluten over the period under study, 
and this correlated with later age of presentation (Spearman's correlation coefficient $r_{s}=0 \cdot 74$, $\mathrm{p}<0.001)$, there was no significant difference when comparing the overall mean $(3.5$ months) with the mean in the first seven years $(1965-71$, mean $=2 \cdot 4$ months) or the last seven years (1979-85, mean $=5.1$ months) by $\chi^{2}$ test (fig 3 ). It is apparent that the trend towards a later introduction of gluten into the diet began before the DHSS recommendation.

BREAST AND BOTTLE FEEDING (TABLE 2)

Overall $46 \%(55 / 120)$ of patients were breast fed. Their median age of presentation was 14 months (range 1-180 months). Bottle fed patients presented at the earlier age of 9 months (range 1-84 months,

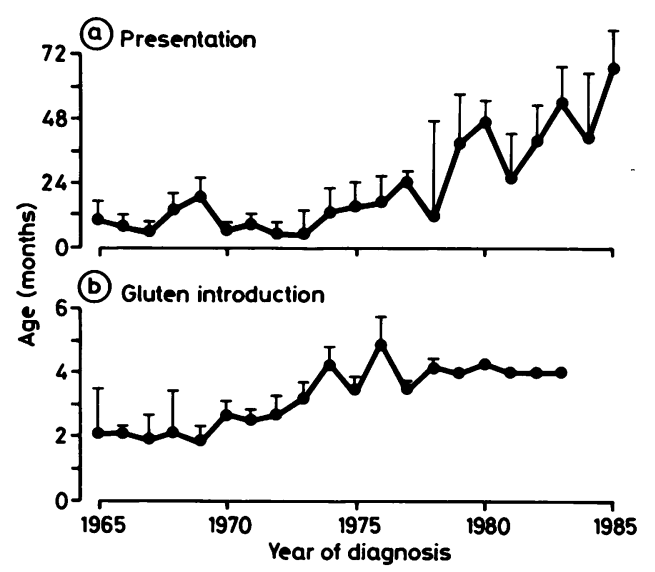

Fig 3 Age of presentation and age of gluten introduction per year of diagnosis. $\mathrm{p}=\mathbf{0} \cdot \mathbf{0 1}$, Mann-Whitney $U$ test). There was no difference in the age of gluten introduction between the two groups. It was apparent that the median age of presentation increased with length of breast feeding ( $<1$ compared with $1-6$ months: $p=0.05$; 1-6 compared with $>6$ months: $p=0.05$ ), although there was no difference in the age of gluten introduction.

Dividing the patients into breast and bottle fed groups before and after 1975 (the date of the DHSS recommendation to delay gluten introduction) showed, in both groups, an increase in the median age of presentation (breast fed $\mathrm{p}=\mathbf{0 . 0 0 4}$, bottle fed $p=0.006)$ and in the time of gluten introduction after $1974(p=0 \cdot 02)$ (Mann-Whitney U test).

\section{ASSOCIATION OF COELIAC DISEASE TO ACUTE} GASTROENTERITIS

Admissions of children with acute gastroenteritis from $1960-85$ increased slightly up to 1973 , they

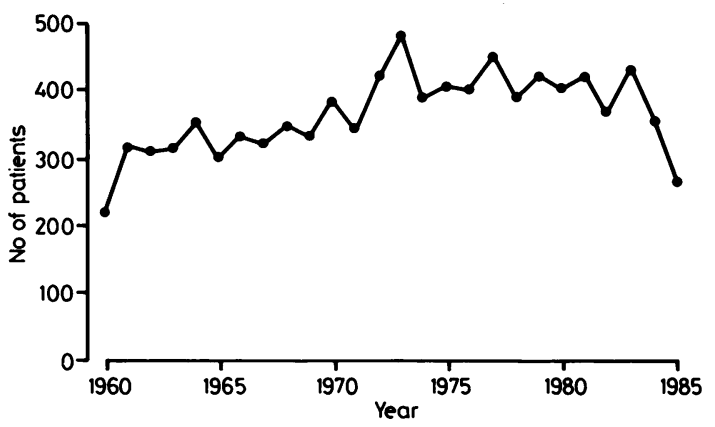

Fig 4 Number of children admitted to Queen Elizabeth Hospital with acute gastroenteritis 1960-85.

Table 2 Breast and bottle feeding: age of presentation and introduction of gluten

\begin{tabular}{|c|c|c|c|}
\hline & No of children & $\begin{array}{l}\text { Median age of gluten } \\
\text { introduction (range) }\end{array}$ & $\begin{array}{l}\text { Median age of presentation } \\
\text { (range) }\end{array}$ \\
\hline \multicolumn{4}{|l|}{ Overall: } \\
\hline Breast fed & 55 & $4 \cdot 0(0 \cdot 1-24 \cdot 0)$ & $14(1-180)$ \\
\hline Bottle fed & 65 & $3.0(0 \cdot 1-7 \cdot 0)$ & $9(1-84)$ \\
\hline \multicolumn{4}{|l|}{ Before 1975: } \\
\hline Breast fed & 24 & $2 \cdot 0(0 \cdot 1-6 \cdot 0)$ & $9.5(1-164)$ \\
\hline Bottle fed & 39 & $2 \cdot 0(0 \cdot 1-6 \cdot 0)$ & $7.0(1-72)$ \\
\hline \multicolumn{4}{|c|}{ After (and including) 1975: } \\
\hline Breast fed & 31 & $4 \cdot 0(10 \cdot 0-24 \cdot 0)$ & $18 \cdot 0(3-180)$ \\
\hline Bottle fed & 26 & $4 \cdot 0(1.0-7 \cdot 0)$ & $10 \cdot 5(2-84)$ \\
\hline \multicolumn{4}{|c|}{ Length of breast feeding (months): } \\
\hline$<1$ & 24 & $3.0(0 \cdot 0-5 \cdot 0)$ & $11 \cdot 5(1.0-6 \cdot 0)$ \\
\hline $1-6$ & 18 & $4.0(1 \cdot 2-6 \cdot 0)$ & $16 \cdot 5(40-164)$ \\
\hline$>6$ & 8 & $4 \cdot 0(4-24)$ & $41 \cdot 0(16-136)$ \\
\hline
\end{tabular}


remained constant to 1983 , and declined subsequently (fig 4).

\section{Discussion}

The numbers of children diagnosed with coeliac disease at Queen Elizabeth Hospital for Children increased slowly up to the early 1970 s, peaked between 1971 and 1975, and gradually declined to levels found before 1971. The observed frequency of diagnosis would not have been found if the incidence of coeliac disease had been constant from year to year, implying that a significant change in incidence occurred from 1971-5.

Although this is not an epidemiological study, it does represent the referral pattern of an east London hospital with a catchment mainly from east London, Essex, and west Kent. Over the time period of the study there has been a specialist interest in coeliac disease throughout and small intestinal biopsies have been performed since 1958 . Other recent studies that have commented on the decline of childhood coeliac disease ${ }^{1-3}$ did not discuss the rise in the early 1970 s that has been noted in both children and adults ${ }^{7}$; this is perhaps because, unlike the studies at our hospital, there was insufficient data collected before 1970. Evaluation of the two peaks of presentation in this study suggest that the minor peak (1960-3) represented histological confirmation of earlier clinical diagnoses; the major peak (1971-4), however, may possibly have been due to increased referral or due to a change in the pattern of infant feeding.

In this study both bottle feeding and early gluten introduction were associated with an earlier presentation as previously suggested, ${ }^{8-10}$ and may have been associated with the documented rise. On the other hand breast fed babies presented later (table 2), and this data supports other studies, which have described a delaying effect of breast feeding on the age of presentation of coeliac disease. ${ }^{10-12}$ It is possible that this may have been associated with better infant hygiene and a decline in infantile gastroenteritis. $^{4}$ The data do not support this, however, as the numbers of children admitted with $\stackrel{5}{\rho}$ acute gastroenteritis over the 25 year period 0 gradually increased up to 1983 . The subsequent $\frac{}{2}$ decline is probably related to better community $\frac{\bar{\infty}}{7}$ education and the care of children as outpatients. $\stackrel{\mathbb{D}}{\triangle}$

In conclusion, the numbers of children diagnosed with coeliac disease rose in the early 1970s, although the reasons for this have not been established by this. study. The subsequent decrease in numbers may be associated with differences in infant feeding in infancy which may cause increasingly later presentation rather than an overall decline in disease incidence.

\section{References}

1 Littlewood JM, Crollick AJ, Richards IDG. Childhood cocliac disease is disappearing. Lancet 1980;ii:1359.

2 Challacombe DN, Bayliss JM. Childhood coeliac disease is disappearing. Lancet 1980;ii: 1360 .

3 Dossetor JFB, Gibson AAM, McNeish AS. Childhood coeliac disease is disappearing. Lancet 1981;1:322-3.

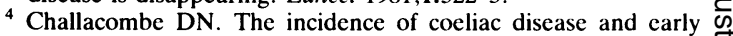
weaning. Arch Dis Child 1983;58:326.

5 Panel on Child Nutrition Working Party on Infant Feeding. Present-day practice in infant feeding. Report on health and social subjects No 9. London: HMSO, 1974:24-6.

6 Meeuwisse GW. Diagnostic criteria in coeliac disease. Acta Paediatr Scand 1970;59:461-3.

7 Langman MJS, McConwell TH, Sigelhalter DJ, McConwell RB. Changing patterns of coeliac disease frequency: an analysis of coeliac society membership records. Gut 1985;26:275-8.

8 Arneil GC. Dietary study of 4365 Scottish infants-1965. Scottish Health Service Studies No 6. Edinburgh: HMSO, 1967:89.

9 Anderson CM, Gracey M, Burke V. Coeliac disease. Some still controversial aspects. Arch Dis Child 1972;47:292-8.

10 Auricchio S, Follo D, de Ritis G, Marubini E. Does breast feeding protect against the development of clinical symptoms of coeliac disease in children. J Pediatr Gastroenterol Nutr 1983;2: 428-33.

11 Polancoe I, Vasquez C, Prieto G, et al. Coeliac disease (CD): influence of breast feeding (BF) and HLA-DR phenotypes on the age of onset of symptoms. Pediatr Res 1982;16:1044.

12 Pittard WB. Breast milk immunology. A frontier in infant nutrition. Am J Dis Child 1979;133:83-7.

Correspondence to Professor JA Walker-Smith, Queen Elizabeth Hospital for Children, Hackney Road, London E2 8PS.

Accepted 17 January 1989 